\title{
FRANCO LELLI Y LA REBELIÓN BUBI DE 1998: HISTORIA Y TESTIMONIO EN OKIRI
}

\author{
STEFANIA LICATA ${ }^{301}$ \\ Stony Brook University
}

Resumen: A través de un acercamiento teórico al género del testimonio y, partiendo de los estudios de John Beverly y Dori Laub, el presente ensayo se propone analizar la novela Okiri (2005) de Franco Lelli, que relata los acontecimientos en torno a la rebelión bubi de 1998 en Guinea Ecuatorial e informa sobre el Movimiento para la Autodeterminación de la Isla de Bioko (MAIB), que se constituyó en 1993. La novela nace de la urgencia de denunciar las injusticias que han oprimido al pueblo bubi, grupo étnico originario de la isla de Bioko, ya desde la independencia de España en 1968; más específicamente, el relato se centra en las violaciones de los derechos humanos por el régimen dictatorial de Teodoro Obiang Nguema, en el poder desde el 3 de agosto de 1979 hasta el presente. Evidenciaré la voluntad documental de la novela, única memoria histórica escrita del acontecimiento, además de subrayar los rasgos subjetivos y testimoniales del relato y distinguirlos de los recursos literarios. Tendré en cuenta la experiencia particular como testigo del autor de la novela, Franco Lelli, que vive la misma atmósfera de represión durante la revuelta, no obstante no forma parte del grupo bubi. El análisis de Okiri no sólo contribuye a la reconstrucción histórica de la rebeldía de 1998 del pueblo bubi, sino que añade otros rasgos al género testimonial.

Palabras clave: Guinea Ecuatorial, MAIB, Testimonio, Derechos Humanos.

AвSTRACT: Through the theoretical approach of testimony and, based on the studies of John Beverly and DoriLaub, this essay analyzes the novel Okiri (2006) by Franco Lelli. Okiri recounts the events related to the 1998 rebellion of the Bubi people in Equatorial Guinea and give information about the Movement for the Self-Determination of Bioko Island (MAIB), that was established in 1993. The novel stems from the urgency to denounce the injustices that have oppressed the Bubi ethnic group, native to the island of Bioko, since the independence from Spain in 1968. In particular, it

301 licata.stefania@yahoo.it 
denounces the violation of human rights inflicted upon them by the dictatorial regime of Teodoro Obiang Nguema, in power since August $3^{\text {rd }}, 1979$ to present. I will analyze the informing nature of the novel, as the only written historical memory of the event. I will stress the testimonial features that characterize the narrative and literary resources, and will consider the experience of Lelli, as a witness who lives the same atmosphere of repression even though he is not part of the bubi group. The analysis of Okiri not only contributes to the historical reconstruction of the bubi rebellion of 1998, but it adds other features to the testimonial genre.

KeYwords: Equatorial Guinea, MAIB, Testimony, Human rights.

\section{Introducción}

John Beverly en “Anatomía del testimonio" (1987) define el género del testimonio como:

"una narración - usualmente pero no obligatoriamente del tamaño de una novela o novela corta- contada en primera persona por un narrador que es a la vez el protagonista (o el testigo de su propio relato). Su unidad narrativa suele ser una "vida" o una vivencia particularmente significativa (situación laboral, militancia política, encarcelamiento, etc.).La situación del narrador en el testimonio siempre involucra cierta urgencia o necesidad de comunicación que surge de una experiencia vivencial de represión, pobreza, explotación, marginalización, crimen, lucha...Debido a su situación vivencial, el narrador del testimonio en muchos casos es o analfabeto o excluido de los circuitos institucionales de producción periodística o literaria" (9)

La novela Okiri (Domani ${ }^{302}$ ) (2005) del cónsul honorario italiano Franco Lelli, que será objeto de este análisis, encaja en el género del testimonio por narrar una "situación de urgencia", aunque complica la definición del género al

302 Mañana

ÉNDOXA: Series Filosóficas, n. ${ }^{\circ}$ 37, 2016, pp. 463-494. UNED, Madrid 
ser el testigo un literato que forma parte de una clase social alta, y que no necesita un intermediario para transcribir su experiencia. El cónsul no es víctima de una opresión personal como en otras narrativas-testimonio tales como Me llamo Rigoberta Menchú y asi me nació la conciencia (1983) escrita por Elizabeth Burgos, pero es testigo de la experiencia bubi y, en palabras de Dori Laub en Truth and Testimony: The Process and the Struggle(1995), es "the immediate receiver of these testimonies" (62). Laub, en el contexto del holocausto, había evidenciado tres niveles de testimonio: ser testigo de sí mismo, de la experiencia de los otros y, ser testigo, al observar el mismo proceso del testimonio. El cónsul italiano se encaja en el segundo y en el tercer nivel de la categoría de testigo de Laub, por haber vivido en Guinea Ecuatorial durante la rebelión y la represión bubi de 1998. Franco Lelli se mudó al país el 20 febrero de 1990 con el objetivo de crear la Sociedad Industrial de Guinea Ecuatorial Soc. Anónima (S.I.G.E.S.A) especializada en el sector forestal. Durante su estancia en Guinea fue nominado cónsul honorario en 1992 y Senador del Parlamento mundial de seguridad y paz en 1997. El 15 de noviembre de 1999 dejó definitivamente Guinea Ecuatorial por razones de salud y en 2003, cuando ya estaba en Italia, fue nombrado consejero diplomático para los negocios en África como se señala en la biografía de la novela.

No obstante el diferente perfil del testigo y la ausencia de su "compilador", Okiri nace de la urgencia del autor por denunciar y contar la tentativa desesperada de rebeldía del pueblo bubi, que ocurrió el 21 de enero de 1998, contra el gobierno dictatorial de Teodoro Obiang Nguema, ${ }^{303}$ y se inserta en el género del testimonio aunque con algunas variantes. Lelli está solo de paso en Guinea Ecuatorial y, aunque relata y novela los hechos de que es testigo desde una perspectiva europea, se acerca con sensibilidad a los trágicos acontecimientos. No es opresor ni tampoco oprimido, es un observador de los hechos y relata con menos dificultad y más pretensiones de objetividad la opresión bubi, por no estar directamente implicado.

303 Obiang es jefe de estado de Guinea Ecuatorial desde el golpe de estado del 3 de octubre de 1979, después de haber derrocado a su tío, y primer presidente del país, Francisco Macías Nguema. 


\section{Okiri y el MAIB}

Okiri se encuadra en un clima de relaciones locales e internacionales complicadas, alrededor del Movimiento para la Autodeterminación de la Isla de Bioko (MAIB), que se constituyó en 1993 en Guinea Ecuatorial con el objetivo de reivindicar los derechos de la etnia $b u b i$, originaria de la isla, oprimida por el gobierno de Obiang. El MAIB se desarrolla bajo la sombra de un gobierno déspota que niega a los bubis todos los derechos básicos, colocándolos en la periferia de Guinea Ecuatorial, por falta de una verdadera representación política en el gobierno, y marginándolos por la falta de oportunidades como grupo social. Algunas organizaciones no gubernamentales como Freedom House o Reporteros sin fronteras sitúan a la Guinea Ecuatorial de los años de la rebelión bubi entre los países más opresivos del mundo, que no sólo no contempla el respeto de los derechos humanos, sino que no se prevé un proceso de avance democrático dentro del sistema gubernamental o electoral.

La novela-testimonio de Lelli destaca por su intento de contribuir a la reconstrucción histórica de la rebelión bubi de 1998, y de la consiguiente fase de intensa represión que se desplegó en Malabo, en el campamento de Rabat y en la cárcel de Black Beach. El narrador-protagonista, que es el mismo Lelli, junto con Josef, su chófer, y Deogracias Ona Monsuy (Deo), un colaborador fang que le ayuda en la actividad forestal, protagonizan todo el relato al que se van añadiendo otros personajes involucrados en el MAIB y en el régimen de Obiang. Lelli empieza el relato con una inspección a una concesión forestal cerca del pueblo de Riaba en el sureste de la isla de Bioko donde empieza la revolución bubi, acompañado de Josef y de Deo. Ya desde las primeras páginas describe un viaje muy incómodo que evidencia que Lelli, en cuanto extranjero, no está acostumbrado al entorno geográfico. La descripción de las condiciones de la permanencia en esta zona de bosque, y de un Land Rover que tenía que llevarlos a Malabo de regreso, eran las causas del sufrimiento de Lelli, cuyo único deseo parecía ser el de volver a destino, pero el coche, en mal estado, se había parado por falta de agua, y la única solución era buscar un arroyo. Durante esta búsqueda Deo, al oír las voces de un grupo de ancianos bubis de los pueblos de Moka y Riaba, decide pararse y escuchar. Es en este entorno cerca del poblado de Basakato de la Sagrada Familia donde Lelli introduce una de las escenas más significativas de toda la novela, describiendo uno de los supuestos lugares reales de encuentro de los miembros del MAIB: 
En un círculo, sentados en el suelo, una docena de hombres discutían animadamente delante de un fuego sin llama. Cada uno tenía a lado su propio candil y un machete clavado en el suelo. La mitad de ellos eran ancianos.En particular, el que estaba hablando y que agitaba el machete tenía que ser el más anciano. En cada pausa de su discurso, los otros intervenían al unísono, como para contestarle. Uno de los miembros del grupo, tal vez el más joven, tenía un cuerpo enorme; sin duda no era un local, y me lo confirmaba el hecho de que no participara en la reacción común en respuesta a lo que el anciano estaba diciendo. El que estaba sentado a su derecha, luego, se acercaba a él de vez en cuando, como para traducirle los discursos. $(2005,14) .304$

La escena con Deo es clave a lo largo de toda la novela ya que él será el personaje fang, casado con una bubi y el único capaz de hablar y entender la lengua bubi, a llevar al lector a conocer a los protagonistas del MAIB. Lelli, como me declaró en la entrevista telefónica del 18 de junio de 2015, había conocido a Deo, ciudadano de Malabo, en Italia durante un curso especializado en la preparación de personal aéreo en un instituto en Terniy; el relato de Deo sobre Guinea Ecuatorial había animado a Lelli a invertir en el país.

Deo, por su experiencia viajando en el extranjero, era el intermediario perfecto en las transacciones con los locales, así como lo será, a lo largo de la novela-testimonio, entre Lelli y los varios miembros del MAIB. Además, su pertenencia a la etnia fang y su conocimiento de los personajes influyentes en el sector político y administrativo del país, que son fang en su mayoría, hubieran podido ayudar a la empresa de madera de Lelli que, durante su estancia entre 1989 y 1999, había creado en Guinea Ecuatorial. Su empresa S.I.G.E.S.A (Sociedad Industrial de Guinea Ecuatorial Soc. Anonima) contaba con 116 empleados locales y estaba compuesta de dos sectores (corte de madera y carpintería) y, en lo específico, 60

304 A circolo, seduti sul suolo, una decina di uomini discutevano animatamente di fronte ad un fuoco senza fiamma. Ciascuno teneva accanto a sè la propria lampada a petrolio e un machete infilzato nel terreno. La meta di essi erano anziani. In particolare, quello che stava parlando e che agitava il machete, doveva essere il piu vecchio. Ad ogni sosta del suo discorso, gli altri intervenivano all'unisono, come a contestarlo. Uno dei componenti del gruppo, forse il piu giovane, aveva una corporatura enorme; certamente non era un locale e me lo confermava il fatto che non partecipasse alla reazione comune in risposta a quanto il vecchio andava dicendo. Il vicino alla sua destra, poi, gli si avvicinava di tanto in tanto, come a tradurgli i discorsi $(2005,14)$.

Todas las traducciones desde el italiano al español son mías. 
estaban empleados en la carpintería. Como Lelli evidencia en la correspondencia electrónica del 27 de agosto de 2015 no resultaba necesario exportar el manufacturado al exterior por el alto número de peticiones internas, tanto del gobierno como de los privados, y solo el $80 \%$ de iroko ${ }^{305}$ estaba destinado a la exportación.

La sociedad de Lelli tenía una licencia exclusiva en la isla de Bioko concedida por el gobierno ya que el primer ministro era su socio. El cónsul evidencia que todas las empresas extranjeras tenían la obligación de tener un socio del gobierno de Teodoro Obiang para crear una actividad comercial en Guinea Ecuatorial. El área en la que Lelli tenía su concesión de madera estaba cubierta en su mayoría de iroko y doussie ${ }^{306}$ pero subraya que el corte tenía que ser autorizado por el Consejo de Ancianos de cada pueblo, aunque fuera pequeño, por la disponibilidad que el Presidente de la República les había asignado. Según nos cuenta, Franco Lelli tuvo que lidiar constantemente con los representantes de los diversos pueblos pero, en la mayoría de los casos, logró convencerlos a pesar de que los guineanos consideren deidades a los árboles. Su sociedad se dedicaba también a la construcción de muebles de alta cualidad al estilo italiano y uno de sus mejores clientes era Teodoro Obiang y su esposa Doña Constancia encantada por el Made in Italy ${ }^{307}$. Durante esa época Lelli dio trabajo a muchos locales hasta que por enfermedad tuvo que vender su actividad antes de volver definitivamente a Italia. $^{308}$

La reunión del MAIB, que relata al comienzo de la novela, se produce en medio del bosque y revela al lector no sólo la clandestinidad del movimiento, sino también la necesidad de financiación por países extranjeros para asegurar el éxito de la rebeldía. El personaje más joven del grupo, al que se traducían los discursos del bubi más anciano, no era un local sino un extranjero, probablemente nigeriano, como se evidenciará más adelante en la novela-testimonio. Lelli, en la correspondencia electrónica del 22 de septiembre de 2013, precisa que el único nigeriano implicado era un militar jubilado que adiestraba a un grupo bubi en

305 El iroko es un tipo de madera de un árbol tropical científicamente llamado Milicia excelsa cuyo duramen es de color amarillo o marrón que se oscurece con el tiempo. http:// www.wood-database.com/lumber-identification/hardwoods/iroko/

306 El doussie es un tipo de madera conocido también como Afzeliacuyo duramen esde color marrónrojizo.

http://www.wood-database.com/lumber-identification/hardwoods/afzelia/

307 Según datos ofrecidos en el correo electrónico del 25 agosto de 2013.

308 Según datos ofrecidos en la entrevista telefónicacon el autor, el 18 de junio de 2015 y en la correspondencia electrónica del 27 de agosto de 2015. 
el bosque, ayudado por un revendedor ambulante de alimentos llamado simplemente Alex. Aclara que el gobierno de Nigeria no estaba involucrado en los eventos y que la presencia de algunos nigerianos en Guinea Ecuatorial se remonta a la época de la colonización española, a comienzos del siglo veinte. De hecho, el gobierno español había reclutado durante el franquismo mano de obra en Nigeria para la explotación de las fincas de cacao de la isla de Bioko, pero fueron repatriados por Francisco Macías Nguema a finales de los años setenta. El grupo de nigerianos, mencionados en el relato, pertenecen a una sucesiva oleada que se mudó a Guinea Ecuatorial y se concentró en el área de Nibiri.

A través del primer capítulo, Lelli da pistas al lector sobre la perspectiva a través de la cual desea que se lea el relato, así como para entender los principios que, en su opinión, animan al Movimiento para la Autodeterminación de la Isla de Bioko. El lector conoce todos los acontecimientos a través de la mirada subjetiva de Lelli pero, al mismo tiempo, es una mirada externa, más distante que la de los otros implicados en el proceso, dado que él no forma parte de ninguna de las etnias del conflicto. La opinión del lector sobre el MAIB se forma a partir de la perspectiva europea del autor y protagonista de la novela, pero también a partir de la perspectiva del personaje de Deo que, paradójicamente, pese a ser fang, conoce las problemáticas de los bubis y es sensible hacia la situación que padecen. Su inclusión con respecto a los acontecimientos es curiosa porque Lelli nos muestra Deo debatirse entre su deber, como fang adicto al gobierno, de denunciar actos rebeldes contra el gobierno de Obiang, y el respeto hacia la familia de su esposa bubi, implicada en el MAIB. El Lelli-narrador enfatiza la posición de Deo porque podría revelar la complejidad y las contradicciones del conflicto étnico dentro de la sociedad guineana.

Paradójicamente, es a través de las conversaciones amigables entre Deo y Lelli, un fang y un europeo, como el autor intenta que el lector perciba la esencia del movimiento de autodeterminación de los bubis. Ya desde el comienzo Deo interpela a Lelli para obtener una mirada objetiva de los hechos. Deo está preocupado por el posible surgimiento de una guerra civil en el país pero, sobre todo, porque están implicados José Nchaso, el padre de su esposa Purita, el tío materno de su esposa y Malabo ${ }^{309}$, el descendiente del rey Bioko, respetado en toda la comunidad por ser poseedor de las antiguas tradiciones. Deo explica el origen del movimiento, y la situación privilegiada de los bubis durante la coloni-

309 Franco Lelli señala en la correspondencia electrónica del 27 de agosto de 2015 que no recuerda el apellido de Purita y del tío materno y no conoce el apellido de Malabo. 
zación española, evidenciando cómo la independencia de España el 12 octubre de 1968, a la que siguió la dictadura de Macias Nguema (1968-1979), había creado el alejamiento de los inversionistas extranjeros. La exportación de cacao y café se había reducido drásticamente, generando el deseo de independencia de la isla.

Según el relato de Lelli, el origen de la fractura entre el pueblo bubi y el pueblo fang, uno de cuyos clanes, los esangui, controla el gobierno del país desde la independencia, se remontaría a la repartición arbitraria de Guinea Ecuatorial durante la colonización, con la unión de la parte insular y continental del territorio. La isla de Bioko (Fernando Poo en la época colonial) pasa de manera efectiva a manos del gobierno espańol en 1858, mientras la parte continental de Río Muni en el año 1900. La unificación de territorios distantes entre sí y conformados por grupos étnicos diferentes ha sido fuente de conflicto desde el comienzo. Robert Sack en sus estudios sobre el espacio geográfico evidencia precisamente la importancia de las relaciones sociales que se establecen en un territorio:

In the primitive view, land is not a thing that can be cut into pieces and sold as parcels. Land is not a piece of space within a larger spatial system. On the contrary, it is seen in terms of social relations. The people, as part of nature, are intimately linked to the land. To belong to a territory or place is a social concept which requires first and foremost belonging to a societal unit. The land itself is in the possession of the group as a whole. It is not privately partitioned and owned. Moreover, it is alive with the spirits and history of the people, and places on it are sacred (citado en Smith, 69)

En el caso de Guinea Ecuatorial, por lo tanto, la agregación de los territorios en la época colonial, y la presencia española, han alterado no sólo la organización originaria de los territorios y las etnias, sino las relaciones sociales y comunitarias, cuya situación ha empeorado con la llegada de la población fang, numéricamente mayoritaria en el país, a la isla de Bioko desde la época colonial.

Lidia Kinson Buetö, viuda de Laesa Atanasio Bitá Rope, ${ }^{310}$ cofundador del MAIB en 1993, y miembro del Comité de coordinación hasta el 2003, lo subraya

310 Laesa Atanasio Bitá Rope fue asesinado, presumiblemente por sicarios pagados por Teodoro Obiang Nguema Mbasogo el 4 de febrero de 2006, durante su exilio en Costa de Marfil para escapar a la persecución de Obiang. El 4 de febrero dos hombres que declararon 
también en el "Diario de comisión de derechos humanos y solicitudes ciudadanas ${ }^{311 "}$ ", del 21 febrero de 2007. La isla de Bioko geográficamente se sitúa más cerca de Nigeria y Camerún que de la parte continental de Guinea Ecuatorial y sólo más tarde se ańadió Bioko, administrativamente, a la parte continental. La cercanía de Nigeria justifica, a la vez, su interés en la isla en cada elección del gobierno nigeriano.

Lelli, en Okiri, pone también de manifiesto, por lo que se refiere a las relaciones entre bubis y fang, que, por lo menos en el pasado, no existieron razones étnicas o religiosas que llevaran a esta fricción, aunque confirma que la pertenencia al territorio sería el objeto de la disputa. Los fang, ya desde la dictadura de Macías, han tenido una situación privilegiada en el gobierno del país, pero la unión entre una mujer bubi y un hombre fang siempre ha sido permitida, aunque no sea frecuente y, por lo general, sea la mujer bubi la que tiene que adaptarse a la tradición fang. El énfasis que pone Lelli en Deo es significativo en este sentido, porque se presenta como testimonio de la posibilidad de unión entre los dos grupos y diferencia la realidad de Guinea Ecuatorial de otras en las que resulta más problemática la unión entre etnias diferentes, como en el caso de los tutsi y butu en Ruanda, que Lelli menciona en su relato.

La persistencia de una situación de desigualdad en el ejercicio del poder podría llevar a la desaparición progresiva de los bubis y de sus tradiciones, a lo que se añade el deseo de rebelarse contra las situaciones de injustica, y todo ello fortalece el proyecto del MAIB. A pesar de que las motivaciones de esa rebeldía parecen justificadas, Lelli desde el principio manifiesta su disidencia hacia una "idea autolesionista dei bubi" $(2005,21)$. Lelli opina que la acción de rebelión bubi carecía desde el principio de las condiciones necesarias para tener éxito y, por esta razón, usa el término "autolesionista” para indicar la autoagresión del pueblo bubi. El regreso hacia Batete, pasando por Moka, para que Deo pueda conversar con la familia de la esposa sobre el plan del MAIB, acerca a Lelli al movimiento de rebeldía y representa una primera toma de conciencia del narrador, de la importancia de la lucha bubi. Sin embargo, la suya es la tenta-

ser agentes del servicio secreto de Costa Marfil lo acusaron de delitos graves en su casa. No obstante él se opuso le ordenaron de salir con ellos y, no obstante la tentativa de Lidia Kinson Buetö de contactar el director general de la seguridad Ogon Dopéa, lo encontraron muerto dos días después de su secuestro. Fue enterrado el 8 de febrero de 2006. (Diario de comisión, 2007 7)

311 El documento se encuentra en el sitio web del parlamento Euskadi y fue publicado el 3/07/09. http://www.parlamento.euskadi.net/pdfdocs/publi/3/07/09/20030411.pdf 
tiva de disuadirlos a realizar el proyecto de rebelión en aquel preciso momento histórico.

La conversación entre Lelli y el anciano Malabo, que tiene lugar en su casa en Moka, será la ocasión para revisitar el periodo de transición entre el fin de la colonización y la independencia que contribuyó a la separación entre los fang y los bubis. Malabo crítica duramente el proceso de independencia de los países africanos, por la falta de un programa de inversión y de una estructura organizativa, aunque, a la vez, la suya es también una fuerte denuncia hacia la acción colonial:

...las fallas de la actual situación económica y social del país no pueden recaer exclusivamente en los guineanos. El espíritu que animó a los colonizadores en todas las partes del mundo nunca se ha inspirado en los principios de altruismo. Se conquistaban nuevas tierras con la idea de beneficiarse económicamente por los desplazamientos y la actitud común de los colonizadores era quedar afuera de los mecanismos de comercio y de la economía los pueblos conquistados, tanto por su falta objetiva de preparación para acceder a la complejidad del nuevo como por la voluntad de mantener secretos esos procesos, listos, de hecho, a suprimir cualquier forma de intromisión indígena que pasara los límites impuestos por los recién llegados ${ }^{312}$. $(2005,27)$

El secretario de relaciones internacionales del MAIB Anacleto Bokesa Camó, exiliado en Madrid desde hace más de 40 años, evidencia, también, en el "Diario de comisión de derechos humanos y solicitudes ciudadanas" (2007) que el gobierno español no ha considerado la perspectiva histórica, la distancia entre la parte insular y continental, y la constitución de la población, considerando que el 75\% formaba parte del territorio continental. Colocar la capital del país en la isla de Bioko, poblada originariamente por los bubis, ha causado la migración de los fang a la capital, Malabo, lo que ha aumentado con el descubrimiento y explotación del petróleo en la isla:

312 ...le colpe dell'attuale situazione economica e sociale del paese non può gravare esclusivamente sui guineani. Lo spirito che ha animato i colonizzatori in ogni parte del mondo non si è mai inspirato ai principi dell'altruismo. Si conquistavano nuove terre con l'idea di trarre benefici economici dagli spostamenti e l'atteggiamento comune dei colonizzatori era di tener fuori dai meccanismi del commercio e dell'economia i popoli conquistati, vuoi per l'oggettiva impreparazione di costoro ad acccedere la complessita del nuovo, vuoi per la volontà di mantenere segreti quei processi, pronti, anzi, a reprimere qualsiasi forma di intromissione indigena che travalicasse i limiti posti dai nuovi venuti." 
Todo el petróleo de Guinea Ecuatorial, que desde 1995 hasta ahora se ha convertido en el tercer productor de petróleo de África, pertenece a la isla de Bioko. No pertenece a la tierra de Obiang ${ }^{313}$. Paradojicamente, ni Honorato quiere ir al país de Obiang ni yo quiero ir a vivir al país de Obiang, pero Obiang no nos permite vivir en nuestro país, donde ha instalado su gobierno, donde ha instalado su población y donde está llevando a cabo una política de expulsión de la población bubi. $(2007,8)$

Según la perspectiva de Bokesa, el proceso de agregación, gestado durante la Conferencia Constitucional que se concluyó con la firma de la independencia de Guinea Ecuatorial en 1968, ha sido la causa del estrago de los bubis. Las problemáticas locales, además, tienen una dimensión internacional, al relacionarse con la explotación de los recursos naturales del país por mediación de compañías transnacionales extranjeras. La referencia al petróleo y a la compañía Exxon Mobil ${ }^{314}$ en la novela explica el interés y la atención hacia la isla de Bioko en la que no sólo el gobierno español lamenta la exclusividad de la compañía americana, sino que también se observa la presión hacia el gobierno de Guinea Ecuatorial por parte del gobierno francés y congolés, para el establecimiento de la empresa de petróleo francesa Elf $^{315}$.

La situación en la que se encuentra la isla de Bioko en el ańo 1998 se complica bastante, y justifica la desconfianza del narrador-protagonista Lelli, y su intento de convencer al MAIB de que renuncie a la acción contra el gobierno de Obiang. En Okiri, mientras Lelli quiere disuadir al MAIB en base a la imposibilidad de tener éxito en una posible revuelta, el anciano Malabo está convencido de la importancia de esta tentativa, aunque no conoce el proyecto global y a todos sus miembros. Lelli informa al lector, además, sobre las implica-

313 La afirmación de Anacleto Bokesa no es exacta porque existen pozos de petróleo que se llevan explotando desde hace años en las costas de la región continental de Rio Muni.

314 La Mobil Equatorial Guinea Inc. (MEGI) es una compañía estadounidense que fue una de las primeras en comenzar las explotaciones en Guinea Ecuatorial, en los años 90. Hoy colabora con la compañía nacional guineana GEPetrol (23.75 por ciento), y el estado de Guinea Ecuatorial (5 por ciento), y tiene su sede de operaciones en Malabo. http://corporate.exxonmobil.com/en/company/worldwide-operations/locations/equatorial-guinea.

315 Elf Aquitaine fue una empresa francesa de petróleo que en 2000 creó la empresa Total S.A. La empresa ya había sido objeto de escándalo en Congo, cuarto productor de petróleo en África, y en 1994, durante la guerra civil del Congo-Brazzaville, ayudó a financiar el golpe de estado del presidente del Congo Denis Sassou Nguesso, que gobierna desde el1997. 
ciones internacionales del movimiento, mencionando a varios activistas guineanos exiliados en España, incluidos políticos fang entre los cuales destaca Severo Moto Nsá ${ }^{316}$. Como evidencia el autor, aunque la rebeldía bubi empieza en el sur de la isla porque allí se puede entrenar a los rebeldes del MAIB con mayor facilidad, el proyecto empieza precisamente en Espańa y en el norte de la isla de Guinea Ecuatorial. Franco Lelli precisa en la entrevista telefónica que la mayoría de los guineanos de etnia bubi residen en España por la dificultad de sobrevivir en Guinea Ecuatorial. La aversión de España hacia el gobierno de Obiang se justifica, entonces, en el cuadro de estas relaciones locales e internacionales que Malabo subraya:

....aquel petróleo es nuestro, pertenece a los Bubis, como habitantes originales de la isla en torno a la cual están haciendo la extracción, pero, una vez más, es Obiang y sus fang los que disfrutan de los beneficios. ¿`No piensas, también tú, que es suficiente para justificar nuestra causa? $(2005,32)^{317}$

Según Malabo, la ideología del MAIB se fundamenta en la idea de la pertenencia a los bubis del territorio y de su explotación y propone el desarrollo económico de la isla, en cuyo proyecto la financiación extranjera resulta esencial. La solicitud de ayuda del suegro de Deo, Don José Nchaso, a Lelli, es en la novela un claro ejemplo de la exigencia de fondos para el éxito del movimiento y, aunque en desacuerdo, Lelli decide ayudarles con dinero para que puedan alquilar medios de transporte para mover a los hombres del movimiento. Lelli aclara en la correspondencia electrónica del 9 de septiembre de 2013 que el MAIB, aunque formado por miembros valientes, es en su opinión un movimiento desorganizado, por la falta de recursos financieros, lo que se subraya en muchos diálogos con los miembros en la novela-testimonio.

La existencia del MAIB la relaciona Lelli también, con la necesidad de preservar las tradiciones que podrían desaparecer con los bubis. De hecho la coexistencia de tradiciones diferentes entre los bubis y los fang en el mismo territorio

316 Severo Matías Moto Nsá es un político originario de Guinea Ecuatorial opositor del régimen de Obiang, exiliado en Espańa desde el año 1981.

317 Quel petrolio è nostro, appartiene ai bubi, come originari abitanti dell'isola intorno alla quale si sta effettuando l'estrazione, ma, ancora una volta, è Obiang e i suoi fang che si godono i vantaggi. Non pensi, anche tu, che ce ne sia abbastanza per giustificare la nostra causa? 
complica las relaciones entre los dos grupos étnicos. Lelli introduce y enfatiza el tema de las tradiciones guineanas en su novela-testimonio a través de la aparición de un cuerpo muerto cerca de la oficina de su carpintería. Había sido asesinado Fernando Micha Edu, de etnia fang, en sacrificio al dios fang Mahò, para que su familia suba de clase social. La víctima había sido elegida ya desde la niñez y considerada un privilegiado en la comunidad.

La explicación que Lelli ofrece de las fases del rito del asesinato abre el tema de la diferencia cultural entre África y Europa. Lelli, escandalizado, denuncia el sacrificio humano en las tradiciones africanas que novela, aunque cuenta los ritos de manera respetuosa evidenciando su punto de vista europeo, pero también su interpretación de la visión africana a través de los personajes en el relato, con la obvia intención de que el lector conozca y reflexione sobre las diferencias culturales tal y como él se las representa. La conversación de Lelli con Deo en la novela quiere hacer patente la presencia de sistemas y de códigos distintos ya que compara la religión católica a los ritos propiciatorios, pero se evidencian igualmente los puntos de contacto:

Los fines borran las diferencias; ambos se articulan en forma original, pero apuntan al mismo objetivo: dar gracias y hacer regalos a la divinidad que regula y armoniza todas las manifestaciones de la vida. $(2005,47)^{318}$

Esta conversación es la ocasión también para enfatizar las tradiciones desiguales entre los bubis y los fang, que complican la convivencia entre los dos grupos étnicos. Lelli precisa que los bubis, aunque no practican el sacrificio humano, se dedican a la magia negra, temida por los fang, y que también la acción del MAIB estaba aprobada por las divinidades bubis, aunque no habían especificado los tiempos para el éxito.

Cabe subrayar que, según Lelli, el MAIB está interesado en la independencia de la isla, y no se propone luchar por cuestiones étnicas como había pasado entre los tutsi-hutu en Ruanda. El genocidio en Ruanda de 1994, en el que los tutsi fueron las víctimas, hacía hincapié en una limpieza étnica, que no es el objetivo del movimiento de autodeterminación de los bubis, aunque se relaciona, también en el caso de Guinea Ecuatorial, con los cambios en las dinámicas sociales

318 La finalità annulla le differenze; ambedue si articolano in forma originale ma puntano al medesimo scopo: rendere grazie e fare doni alla divinità che regola e armonizza tutte le manifestazioni della vita. 
entre los grupos originarios. También en Ruanda la falta de conocimiento del colonizador belga sobre el sistema africano creó la división y el conflicto entre los tutsi, los hutu y los twa.

La historia se complica cuando Lelli enfatiza el rasgo internacional del acontecimiento, a través de la convocatoria del presidente Obiang a todos los extranjeros para informarles de que Angola, país amigo de Guinea Ecuatorial, había encontrado un barco con armas que se dirigían hacia las islas guineanas, lo cual creaba sospechas sobre un posible golpe de estado al gobierno coadyuvado por fuerzas internacionales. El mensaje amenazador de Obiang a todos los empresarios internacionales confirma, en la novela-testimonio, las alusiones hechas en varias escenas por los miembros-protagonistas del MAIB a un sistema de gobierno que niega los principios de una república cual es Guinea Ecuatorial:

Pero si contrariamente de lo que pienso, debe haber algunos de ustedes involucrados en este negocio sucio, entonces, a partir de ahora, éstos tienen 24 horas para abandonar el país, haciéndome responsable de su seguridad personal en este marco de tiempo. Después del plazo, no sólo no voy a ser más responsable de su vida, sino voy a dejar el asunto a nuestro Tribunal Militar, que juzgará sobre la base de las leyes vigentes en Guinea Ecuatorial. A partir de ahora, les digo que no voy a permitir a cualquier Embajada, organización internacional o entidad no gubernamental, aterrizar en la isla con el fin de llevarse a nadie, culpable de este crimen, que haya tratado de ocultarlo y de perseguir su intención criminal. Tendrá que enfrentarse con nuestra justicia en la misma forma en que ésta actúa contra cualquier ciudadano ecuatoguineano $(2005,56-57)^{319}$

Como señala Lelli en la correspondencia electrónica del 25 de agosto de 2013, en la que declara conocer al presidente Obiang y a su esposa Constancia por la pasión de ambos hacia el estilo italiano, es evidente que Guinea, aunque

319 Ma se contrariamente a quanto penso, ci dovesse essere qualcuno di voi implicato in questa sporca faccenda, allora, a partire da ora, questi ha 24 ore per lasciare il paese, facendomi garante della sua incolumità personale in questo lasso di tempo. Trascorso il termine, non solo non sarò piu garante della sua vita, ma affiderò il caso al nostro Tribunale Militare che giudichera sulla scorta delle leggi vigenti in Guinea Equatoriale. Fin d'ora, vi dico che non consentirò a nessuna Ambasciata, organizzazione internazionale o entità non governativa di atterrare sull'isola con lo scopo di prelevare chiunque, macchiatosi di quest'infamia, abbia tentato di nasconderla e di perseguire il suo intento criminoso. Dovrà affrontare la nostra giustizia con le stesse modalità con cui questa agisce nei confronti di un qualsivoglia cittadino equatoguineano. 
formalmente es una república, la lógica del gobierno es dictatorial. Dentro del partido democrático del presidente Obiang (PDGE) se constituyó el grupo $<<$ Amigos de Obiang $>>$, fieles a la voluntad del dictador, que tienen el deber de denunciar cualquier desorden. Deo es precisamente uno de los miembros del grupo $<<$ Amigos de Obiang $>>$ y se justifica, por lo tanto, su miedo en el relato de Lelli a implicarse en los acontecimientos. Según su testimonio, además, el barco con las armas en Angola y las acciones del MAIB no estaban interconectados, sino que representaban dos tentativas diferentes de rebelión contra el gobierno de Obiang. En Okiri, los miembros del MAIB lo interpretan como una señal positiva porque, de esta manera, el gobierno habría tenido que concentrarse en la otra acción de rebelión, aunque el MAIB en esta tentativa no tendrá éxito.

A pesar de las sospechas que empiezan a crearse en el país, sólo a través de la amistad que Lelli tenía con Chico Ndong, jefe de la Guardia presidencial, puede atravesar con facilidad, junto con Deo y Josef, los puestos de control militar que habían sido instalados a lo largo de la isla de Bioko. Pudieron moverse de una parte a otra por carretera, llegar a Musola para adquirir los árboles de las fincas de Reginaldo y encontrar al anciano Malabo, al cual Lelli pide que le acompañe a Ureka para asistir a los ritos tradicionales bubis. Lelli no sólo quiere satisfacer el interés y la curiosidad en cuanto a la cuestión bubi, y conocer la isla y su gente, sino también adentrarse en los rituales, que forman parte del cuadro moralizante de la novela. La ceremonia antes del corte del árbol revela una espiritualidad y un apego a la tierra que justifica la importancia del territorio y del proyecto del MAIB para los bubis. Su dios se identifica con los árboles y, por esta razón, usan la madera sólo para crear las máscaras y se alimentan sólo de los productos de la tierra (los tubérculos como el ñame, malanga, o yuca). Lelli interpela a la conciencia del lector para que reflexione sobre el diferente acercamiento a la tierra y a la naturaleza, que valorizan sin explotar. La exigencia de Lelli de visitar Ureka se justifica en este deseo de transmitir al lector la sacralidad de los lugares menos contaminados por el proceso colonial.

El encuentro con Ankalì, el suegro de Malabo, es otra ocasión para que el lector se acerque a los ritos tradicionales y a la espiritualidad de las comunidades ancestrales. Lelli presenta a Ankali como el jefe de la aldea de Ureka y le describe como un hombre de casi dos metros de altura, de sesenta años, con una barba blanca y rizada que casi le cubría su rostro. Vivía en la choza más grande del pueblo y en el lugar más alto, desde donde dominabalos otros edificios. Era flemático y parecía que sentenciaba cada vez que hablaba, sin duda influenciado 
por el papel que desempeñaba ${ }^{320}$. A través de la conversación con Ankalì Lelli transmite el mensaje moralizador que domina toda la novela, y que en la cita que sigue se expresa a través de una reflexión sobre el mañana:

El Mañana, en nuestra cultura, es la certidumbre -añadió además -así como para los fang.Es el equivalente de vuestro hoy. Quizá la explicación está en el hecho de que tenemos una visión de la vida más próxima a las verdades de la naturaleza, que nos transmite mayor seguridad en el futuro y en la interpretación de lo que nos rodea. Pero esta capacidad, no es un regalo, nos la hemos ganado con el tiempo, nunca interrumpiendo la conversación con todo lo que vemos alrededor y que da un sentido ordenado a la vida del individuo y del grupo. Vosotros habéis cortado el cordón umbilical con la naturaleza. Todo lo que ves a tu alrededor, estos árboles, las aguas del océano, las aves, estarán también mañana y darán los mismos frutos que hoy. Vuestra actitud es de recoger todo hoy porque no estáis muy seguros de que el mañana pueda todavía existir: la diferencia entre nosotros es ésta, os falta la certidumbre del mañana $(2005,88-89)^{321}$

Lelli se sirve del personaje de Ankalì para denunciar el neocolonialismo enviando un mensaje fuerte y explícito a su lector sobre la cuestión africana. Aunque la novela-testimonio se publica en Italia en el año 2005, Lelli en efecto no se dirige sólo al público italiano, sino que es un mensaje que engloba a todos los países que han tenido y siguen teniendo intereses económicos en África, obstaculizando un desarrollo integral del continente. La independencia de los países africanos y el fenómeno de la descolonización han sido cuestionadas por muchos críticos y Okiri usa precisamente la filosofía del mañana para entrar en la discusión sobre los efectos que la globalización ha causado en comunidades con una lógica diferente, en estrecho contacto con la naturaleza. La atención de Lelli

320 Según datos ofrecidos por el autor en el correo electrónico del 27 de agosto de 2015.

321 Il domani, nella nostra cultura, rappresenta la certezza- aggiunse ancora- cosi come per i fang. È l'equivalente del vostro oggi. Forse la spiegazione sta nel fatto che abbiamo una visione della vita piu prossima allae verità della natura, tale da trasferirci piu sicurezza nel futuro e nell'interpretazione di quanto ci circonda. Ma questa capacità, non è un dono, ce la siamo conquistata nel corso del tempo, non interrompendo mai il colloquio con tutto ciò che vediamo intorno e che dà un senso ordinato alla vita del singolo e del gruppo. Voi avete tagliato il cordone ombelicale con la natura. Tutto quello che vedi intorno a te, questi alberi, le acque dell'oceano, gli uccelli, ci saranno anche domani e daranno gli stessi frutti di oggi. Il vostro atteggiamento è di cogliere tutto oggi, perche non siete più certi che domani ci possa ancora essere: la differenza fra noi è tutta qui, vi manca la certezza del domani. 
hacia lo que él se representa como las tradiciones bubis y fang se justifica a partir de esta filosofía y su intento es también el de dar la llave al lector para que acceda a tradiciones que no pertenecen a su cultura. Revalúa las ideologías africanas, aunque manifiesta no comprender algunas tradiciones, y pone de manifiesto la ignorancia europea sobre el continente.

Como señala Bokesa en el "Diario de comisiones" (2007), fue el desconocimiento de la cultura africana lo que contribuyó a una repartición arbitraria de los territorios y a las problemáticas del continente africano. A pesar de la atención internacional al caso africano y, en el presente análisis, al caso guineano, que se evidencia en Okiri con las referencias a las noticias difundidas por Radio France International y Radio Exterior de España sobre la existencia del MAIB y la opresión de los bubis; no se concretizan soluciones para que sean garantizados los derechos humanos a todos los grupos étnicos.

Los controles a lo largo de todo el país, los visados denegados, las torturas y las matanzas caracterizan el clima de la última parte del relato, a pesar de que Amnistía Internacional y los activistas residentes en España solicitaron y solicitan el respeto de los derechos de los bubis. Cada estado, como señala Jack Donnelly en su libro Universal Human Rights(1989), tiene la autoridad, pero también la responsabilidad, de asegurar a todos los ciudadanos sus derechos. El sistema de los derechos humanos es un mecanismo que ayuda a controlar la relación entre el estado y sus ciudadanos, pero en el caso guineano no existía esta relación, lo cual explica la presencia de los desequilibrios. La situación en la que se encuentra el gobierno de Obiang en el año 1998 es la de luchar no sólo contra el MAIB, sino también contra los políticos opositores a su forma de gobierno. Como apunta Lelli, una acción combinada hubiera podido ser una solución, pero el comienzo de una división étnica impedía la seguridad del éxito conjunto.

Según el relato novelado de Lelli, el 20 de enero de 1998 arranca en Luba la acción bubi que, con la ayuda de mercenarios nigerianos, se dirigen al campamiento militar más cercano, al que neutralizan, y se ponen en contacto con Don Josè Nchaso en Moka, que transmitirá las informaciones de la acción a Baney. No obstante el éxito, aunque sangriento, de las primeras acciones del MAIB, el ejército de Obiang había sido informado de los ataques bubis y del avance hacia Malabo y comenzó enseguida a organizar una contraofensiva para bloquear la marcha en los frentes del oeste y del este de la isla, con Chico Ndong y Melanio Owono como comandantes. Los discursos del presidente Obiang contra los rebeldes, acompañados por el himno nacional en la radio, eran frecuentes. Los 
soldados de la Seguridad Nacional, mandados por Chico Ndong, esperaban a los hombres del MAIB para el ataque frontal en una posición privilegiada. Un trágico error de los bubis sobre la posición de ataque de los soldados de Ndong marcó el final de su estrategia de avanzada:

El trágico error marcó el fin del sueño bubi; Chico Ndong abrió fuego cuando los rebeldes estaban ya a unos treinta metros de su posición, presionados por el ataque militar de Bata, que sofocaron en un dominio absoluto sus esfuerzos y sus esperanzas. En vano valieron los aislados y heroicos episodios de resistencia; los del MAIB ni siquiera trataron de escapar en las calles citadinas, prefiriendo caer bajo el fuego en las acciones suicidas, en lugar de rendirse vivos en las manos de los fang. La calleja estaba llena de cuerpos; Mohammed mismo eligió morir luchando, así como Anastasio, y uno por uno, los hombres del grupo. $(2005,132)^{322}$

Lelli, en la entrevista telefónica del 18 de Junio de 2015, destaca que sólo en la parte en la que cuenta las fases de la rebelión ha añadido detalles ficticios para que el lector pudiera seguir el hilo de los acontecimientos. Como él ya había mencionado, el MAIB era en su opinión un movimiento comprometido políticamente, pero desorganizado por falta de recursos financieros, lo que justifica la elección de Lelli de incluir elementos ficticios en los últimos capítulos de su novela-testimonio. Estupros, robos, violencias físicas en el campamiento de Rabat, durante el indagatorio de Chico Ndong y de Armengol Ondo Nguema (hermano del presidente y Jefe de la Policía Presidencial ${ }^{323}$ ) contra hombres,

322 Il trágico errore segnó la fine del sogno bubi; Chico Ndong apri il fuoco quando i rivoltosi erano gia a una trentina di metri dalla sua postazione, incalzati dall attacco dei militari di Bata, che soffocaron in una stretta mortale i loro sforzi e le loro speranze. A nulla valsero gli isolati ed eroici episodi di resistenza; i MAIB non cercarono neppure la fuga per le vie cittadine, preferendo cadere sotto il fuoco nemico in azioni suicide, piuttosto che consegnarsi vivi nelle mani dei fang. Il viale era cosparso di corpi; lo stesso Mohammed scelse di morire combattendo, cosi come Anastasio, ed uno ad uno, gli uomini del gruppo.

323 Según datos ofrecidos en el correo electrónico del 28 agosto de 2015 Franco Lelli lo describe como un persona cruel, sin escrúpulos, y dispuesto en cualquier momento a mostrar la brutalidad y la crueldad de los métodos dictatoriales. Èl posee varias empresas de importación en exclusiva de bienes primarios, como medicamentos, harina y otros. Ha sido fuente de preocupaciones también por el mismo Teodoro Obiang que ha temido un golpe de Estado. 
mujeres y niños bubis, que Lelli recoge a través de testimonios orales, caracterizan los últimos capítulos de la novela-testimonio y subrayan la violencia inimaginable de los colaboradores de Obiang, además de marcar de manera indeleble la historia de los bubis.

Lidia Kinson Buetö, en el "Diario de comisión” (2007) lamenta, también, la condición y la violación de los derechos humanos, precisamente en la rebelión del 1998, que Lelli investiga para redactar su novela:

El 21 de enero de 1998, cerca de un centenar de jóvenes bubis protagonizaron un intento de rebelión popular contra la dictadura de Obiang. El dictador no se contentó con sofocar la rebelión y detener a los autores de la protesta, sino que desencadenó una autentica orgía de violencia contra la totalidad del pueblo bubi. Más de 800 personas fueron detenidas, torturadas, y muchas mutiladas por tener, o no, alguna relación con los hechos. Bastaba con ser familiar de cualquiera de los supuestos implicados, bastaba con vivir en el mismo pueblo, bastaba con ser bubi. $(2007,6)$

La aparición de Teodoro Obiang en el penúltimo capítulo de la novela es la culminación de la violencia. Después de la rebelión bubi ordena a todos los extranjeros que se quedaron en el país destruir los cayucos y matar a todos los colaboradores que no pudieron capturar, sobre todo a los principales miembros del MAIB, como Vicente Bokara y Don Josè Malabo. Lelli recuerda, también, en estas páginas la crueldad de Teodoro Obiang cuando sacó del poder a su tío Macías Nguema, en 1979, como señala también Randall Fegley en Equatorial Guinea. An African Tragedy (1989).

Según lo que relata Lelli, el deseo de independencia del pueblo bubi nace de una opresión que se remonta a la independencia de Guinea Ecuatorial, en 1968, y la novela da pistas al lector sobre la larga represión de la población bubi. El

Se rumoreaba que a crear el caos había sido el hijo del Presidente, Teodorín, que notoriamente es mal tolerado por su tío.Armengol espera desde mucho tiempo suceder a su hermano Teodoro que sufre de cáncer de próstata pero la presencia de Teodorín ha afectado las posibilidades concretas de substituir a su hermano en la presidencia. 
coraje de los miembros del MAIB se revela hasta el final de la novela-testimonio. El último interrogatorio del político guineano Martin Puye Topepé, que con orgullo expresa su pertenencia al movimiento y la importancia del sacrificio, es el perfil de un héroe que, junto con los otros, ha dado su vida en la rebelión de 1998.

Los días sucesivos a la insurrección fueron de gran agitación, porque el gobierno tenía que mostrar su poder y evitar el surgimiento de otros movimientos. Como recuerda Lelli en la correspondencia electrónica del 22 de septiembre de 2013, los militares intervinieron también después de la rebelión, concretamente el 25 de enero de 1998, para aplacar el surgimiento de una protesta, y el 26 de enero entraron en la misión <<Jesús y María >>, en el barrio Lampert, para violar exclusivamente a las huérfanas bubi. Estos acontecimientos, juntos con otros, crearon el comienzo de un odio racial que ha ido endureciendo las relaciones entre los dos grupos étnicos.

La acción de los medios de comunicación ha contribuido, además, al propósito de Obiang de diseminar el odio étnico a través de informaciones equivocadas según las cuales el propósito de los bubis en la rebeldía era matar a los fang o, como puntualiza Lelli, se difundió la información de un mayor número de miembros del MAIB, que en realidad correspondían a sólo 32 unidades, para exaltar la grandeza del ejército de Obiang que los había derrotado.

Sólo una semana después, el 27 y el 28 de enero, el gobierno de Obiang recibió una solicitud internacional para que pusiera fin a la crueldad con que se trataba a los presos en la cárcel de Black Beach. Los prisioneros vivían en condiciones inhumanas y eran objeto de torturas. Lelli describe en el relato cuatro habitaciones con más de cien prisioneros, desnudos y con señales evidentes de la tortura recibida, siendo las más visibles piernas y brazos fracturados y orejas mutiladas. No se respetaba tampoco la dignidad de los cadáveres, que fueron puestos en un almacén en Malabo.

En la entrevista telefónica del 18 de junio de 2015, Franco Lelli relata que el 1 de febrero de 1998 la policía gubernamental mató a muchas familias de Rebola, acusados de haber ayudado a los rebeldes, pero para que las organizaciones internacionales no quitasen las ayudas financiarías al país, los cadáveres fueron ocultados en el bosque y el presidente intentó disminuir la acción del MAIB para demonstrar la estabilidad de su gobierno. Muchos miembros del MAIB, entre ellos Mansueto Loeri, Silvestre Orichi, o Enrique Boneque, desafortunadamente 
desaparecieron, o intentaron huir. La atención internacional hacia el acontecimiento obligó a Obiang a un proceso más regular, que empezó el 23 de marzo del mismo año, aunque intentó acelerarlo para que no se revelaran los crímenes de su gobierno.También en esta ocasión el uso de los medios de comunicación y de los testimonios en la televisión de los rebeldes, y de los religiosos, que habían ayudado a los bubis, como Eduardo Lesohao Bienvenido Samba, servía para disuadir de otros ataques al gobierno.

La novela-testimonio termina con el regreso en avión de Lelli a Italia, a causa de la malaria y con su reflexión sobre su misma experiencia en Guinea Ecuatorial:

Me acordé de mi primer viaje a África, sin darme cuenta de lo peligroso de las novedades que habría encontrado, con muchos proyectos en la cabeza y el espíritu del misionero. Diez años más tarde, llegué a la conclusión de que había recibido mucho más de lo que había dado. Sentía que había sido injusta mi presencia en aquella comunidad y de haber traído ejemplos de civilizaciones no necesarios, dejando para bien o para mal los signos de mi diversidad en el orden de su sistema. Y como cualquier buen colonizador, me había enriquecido a sus costas de la concepción sencilla de la vida, de la fuerza de sus creencias, de la esperanza inquebrantable en un mundo mejor. $(2005,150) .^{324}$

Franco Lelli termina su novela con una toma de conciencia y una reflexión sobre el colonialismo europeo en África, el anterior a las independencias, y el posterior. Desde su posición de europeo se acerca de manera sensible a la cuestión bubi, y transmite un mensaje moralizador que rodea todo el relato a través de la filosofía del mañana.

${ }^{324}$ Mi venne in mente il mio primo viaggio in Africa, all'oscuro dei pericoli o delle novità che avrei incontrato, con mille progetti in testa e lo spirito del missionario. Dieci anni dopo, mi ritrovavo a concludere che avevo ricevuto molto più di quello che avevo dato. Sentivo che era stata ingiusta la mia presenza in quella comunità e di aver portato esempi di civiltà non richiesti, lasciando nel bene o nel male, segni della mia diversità nell'ordine del suo sistema. E come ogni bravo colonizzatore, m'ero arricchito a loro spese della concezione semplice della vita, della forza delle loro credenze, della speranza incrollabile in un mondo migliore. $(2005,150)$. 


\section{Conclusiones}

Okiri (domani) es el resultado de un compromiso personal contra las injusticias en Guinea Ecuatorial, y un testimonio novelado sobre la rebelión bubi de 1998 en la isla de Bioko. Lelli se sirve del género de la novela-testimonio para relatar un momento dramático en la historia reciente de la isla, y reconstruir una página de la resistencia oculta de Guinea Ecuatorial con fechas y personajes reales. Es el "efecto de veracidad" que caracteriza el testimonio y Okiri narra acontecimientos reales, tal y como los recuerda o los reconstruye su narrador y reordena las acciones del MAIB sólo en la descripción de la rebeldía. Retomando la teorización que hace John Beverly sobre el testimonio, Okiri encajaría perfectamente en el género testimonial por el carácter documental del relato y la voluntad de precisión histórica, además de la urgencia que marca el tiempo del relato, al describir un contexto de terror, de opresión y de venganza. Okiri se distancia del género tradicional del testimonio sólo en el perfil del testigonarrador, que en este caso no es el excluido de los círculos de poder que habla hacia la "ciudad letrada", sino que es un sujeto empoderado, que no fue víctima sino sólo testigo externo de los hechos, y que con su propia voz logra interpelar la conciencia del lector occidental. Lelli es el intermediario perfecto para el diálogo con el occidente; observa la opresión y participa de ella emocionalmente, y la denuncia sin resquemor.

La ausencia de informaciones verídicas sobre los trágicos acontecimientos de 1998 en Guinea Ecuatorial, y el rápido proceso del 23 marzo del mismo año sobre la masacre de los bubis, bajo presión de las potencias internacionales, evidencian la construcción por parte del gobierno guineano de un proyecto nacional cuya narración resulta fragmentada y Franco Lelli, a través de su novelatestimonio, intenta recomponer estos fragmentos y dar voz a un pueblo que sigue luchando. Su novela, junto con los testimonios de los miembros del MAIB en el "Diario de comisión de derechos humanos y solicitudes ciudadanas" del 21 febrero de 2007, son ejemplos contundentes de denuncia, y contribuyen de manera definitiva a que no se olviden las víctimas del pueblo bubi bajo el régimen de Obiang en la década de los años 90. 
APÉNDICE: Comparecencia de Lidia Kinson Buetö ante la Comisión de Derechos Humanos del Parlamento Vasco el día 21 de febrero de $2007^{325}$

Egun on, señor presidente, señoras y señores diputados. Gracias por permitirme comparecer ante ustedes.

Mi nombre es Lidia Kinson Buetö, viuda de Laesa Atanasio Bitá Rope, asesinado el 4 de febrero del 2006 por sicarios de Teodoro Obiang Nguema, dictador de Guinea Ecuatorial, por defender los derechos del pueblo bubi.

Mi marido fue cofundador del Movimiento para la Autodeterminación de la Isla de Bioko (MAIB) el año 1993, miembro del Comité de Coordinación de dicho Movimiento hasta el año 2003 y presidente del mismo desde ese año hasta el día de su secuestro y asesinato. El motivo por el que le asesinaron fue, sin duda alguna, su completa entrega a la actividad política como líder del pueblo bubi.

Por eso, el objetivo de mi comparecencia ante ustedes tiene dos aspectos complementarios:

En primer lugar, deseo solicitar su apoyo para lograr que el Gobierno de España y la instancia judicial que para ello pueda ser competente promuevan una investigación que permita el esclarecimiento del asesinato de mi marido y la responsabilidad del dictador de Guinea Ecuatorial en su instigación y ejecución. Una investigación que permita que se haga justicia y que los culpables de la muerte de Bitá Rope sean hallados, juzgados y condenados.

En segundo lugar, creo que es para mí un deber de fidelidad hacia mi marido pedir a este Parlamento y al pueblo vasco al que representa, su solidaridad con el pueblo bubi en su justa lucha por la democracia y el derecho a la autodeterminación, que me permitan ustedes hablarles de la opresión del pueblo bubi por la dictadura de Teodoro Obiang y del asesinato de mi marido.

Lo que hoy es Guinea Ecuatorial fue territorio español hasta 1968; desde 1777 en el caso de la Isla de Bioko, con los Tratados de San Ildefonso y de El Pardo, y desde 1900 en el caso de Río Muni, por medio del Tratado de París. Sin embargo, durante los meses que llevo en la península he podido comprobar, con

325 Parlamento Vasco. Comisión de Derechos Humanos y Solicitudes Ciudadanas. VIII legislatura. Diario de Comisiones (21.02.2007) 
sorpresa y con tristeza, que la inmensa mayoría de las personas que he conocido no saben de la existencia de Guinea Ecuatorial, ni mucho menos saben de la existencia de mi pueblo, el pueblo bubi.

Sin entrar en detalles les diré que los bubis somos los primeros pobladores de la isla de Bioko, la población nativa originaria con la que se toparon en la isla los primeros colonizadores europeos. Un pueblo lingüística y culturalmente diferenciado de otros grupos étnicos de Guinea Ecuatorial, como los fang, los ndowé o los annoboneses.

La isla de Bioko, una superficie de 2.017 Kilómetros cuadrados, con una población estimada de 70.000 habitantes, está geográficamente mucho más cerca de otros países del golfo de Guinea, como Nigeria o Camerún, de cuya costa le separan $32 \mathrm{Km}$., que del territorio continental de Guinea Ecuatorial que está a más de 350 Kilómetros por mar.

El único motivo por el que dos territorios tan separados geográficamente y con población de lengua y cultura tan diferentes como los bubis y los fang forman hoy parte del mismo Estado es que ambos territorios fueron colonizados por España y, por consiguiente, sus respectivas poblaciones fueron obligadas a convivir en el marco de un mismo Estado cuando la ONU presionó a España en 1968 para que se desprendiera de sus colonias africanas.

La dominación colonial española es, por tanto, el único motivo de que los bubis, inicialmente los únicos pobladores de la isla de Bioko, seamos hoy, demográfica y políticamente, un colectivo marginado dentro de Guinea Ecuatorial.

La decisión española de unir en 1968 la isla de Bioko y el territorio continental de Río Muni en un Estado, en contra de la voluntad del pueblo bubi, nos condenó a la condición permanente de minoría étnica discriminada por la mayoría fang, dada la estructura demográfica del nuevo Estado.

Pero lo peor estaba por llegar: la dictadura de Macías Nguema, quien entre 1968 y 1979 condenó a la miseria, al hambre, a la prisión, a los campos de trabajo, al exilio o a la muerte a buena parte de la población guineana. Pero hasta en el horror hay grados: la suerte que a un guineano le esperaba bajo Macías era tanto peor cuanto más lejos estuviera del núcleo familiar, clánico y clientelar del poder tiránico, y los bubis estaban en el círculo más alejado del llamado "clan de Mongomo", que rodeaba al dictador. 
En tiempos de Macías, con un bubi todo estaba permitido en Guinea. Macías procedió al asesinato de Pastor Torao Sikara, de Edmundo Bosio Dioko, de Enrique Gori Molubela y de todos los líderes políticos bubis, los altos funcionarios y hombres de negocios bubis, paralizando así la vida política y socio-económica de nuestro pueblo y sembrando el terror.

La creciente locura criminal de Macías acabó por alcanzar y amenazar incluso a los más cercanos a él y, como consecuencia, fue su propio sobrino y principal corresponsable de sus crímenes como ministro del Interior, Teodoro Obiang Nguema, quien le derrocó en 1979 en el llamado, con sarcasmo, "golpe de la libertad".

Tras el golpe de 1979, Obiang hizo promesas de libertad que pronto se revelaron como un burdo engaño para atraer a opositores exiliados, a los que pronto volvió a marginar y a perseguir. Hoy, el Estado guineano sigue siendo un aparato de represión y de rapiña, al servicio exclusivo del "clan de Mongomo", y de su tupida clientela periférica. Un aparato de poder para el que la población guineana es sólo un objeto de robo, de chantaje, de amenaza y de violencia arbitraria.

El Estado guineano es más parecido a una mafia institucionalizada y legalizada que a un Estado de Derecho. En esa mafia organizada en torno a una familia, a un clan y a un distrito, un bubi sólo puede entrar como siervo sumiso, con lo que los anhelos bubis de democracia y autodeterminación son tan acallados y reprimidos como en tiempos de Macías.

Hasta el descubrimiento del petróleo a comienzos de los 90, esa mafia nguemista, de la que Obiang ha sido y es el gran padrino, se enriqueció y consolidó su poder extorsionando a las empresas madereras que explotaban el bosque ecuatorial y poniendo su red diplomática internacional al servicio del narcotráfico, a la vez que quedándose con la ayuda económica para el desarrollo proveniente de los países europeos, especialmente de Espańa.

Formalmente, esta ayuda se autoproclamaba condicionada a la democratización del Estado y al respeto a los derechos humanos, asignaturas éstas en las que el régimen nguemista ha estado siempre muy lejos del aprobado. Curiosamente, a medida que la presión diplomática española e internacional aparentaba incrementarse, Obiang se fue poco a poco especializando en la picaresca diplomática, en jugar con Espańa y Francia para vender Guinea al mejor postor, en el maquillaje democrático de su dictadura, y en la periódica repetición de 
oleadas represivas y depuraciones internas con el pretexto de supuestos intentos de golpes de Estado.

En ese marco hay que situar el teatro democrático iniciado a comienzos de los años 90, la parodia del multipartidismo, la legalización e ilegalización arbitraria de partidos políticos, más o menos títeres, la organización de elecciones amañadas y la puesta en marcha de un Parlamento fantasma que, cuando no vegeta y languidece, fabrica leyes para un Ejecutivo que ni las desea, ni las lee ni las respeta.

Mi marido y el Movimiento para la Autodeterminación de la Isla de Bioko que él lideraba nunca aceptaron el papel de comparsas en esa comedia, y eso les condenó a la clandestinidad y a la represión.

Después llegó el petróleo, y con él el manto protector de los Estados Unidos a la dictadura, mejor dicho de las grandes compañías petrolíferas norteamericanas, aún menos sensibles que su Gobierno a entelequias como el respeto a los derechos humanos, sin relación directa con la rentabilidad económica.

Desde mediados de los 90, la mafia nguemista, a la que la pobreza del país le obligaba antes, para enriquecerse, a mendigar la ayuda internacional y a robar como podía, disfruta del maná del petróleo que le permite amasar grandes fortunas y consolidar su poder mientras la inmensa mayoría de la población guineana sigue condenada a la miseria, al desempleo, a la desnutrición, a la enfermedad, al analfabetismo y a la muerte prematura. Baste decir que, en los últimos cinco años, al mismo tiempo que el país ha ascendido a los puestos más altos de África en renta per cápita, la esperanza de vida ha descendido de los 49 a los 45 años.

Ebria de riqueza y de poder, protegida por algunas democracias occidentales y por las multinacionales del petróleo, la mafia de Obiang ha incrementado su capacidad de corromper políticos y de comprar antiguos opositores, y ha ampliado el círculo de clientes y de siervos que se benefician de las migajas del petróleo, reservando para quienes se niegan a someterse, como el Movimiento por la Autodeterminación de la Isla de Bioko (MAIB), la cárcel, la tortura y la muerte.

Bajo esta realidad histórica, social y política se enmarca el asesinato de mi marido. Una realidad que ya ha sido expuesta y denunciada por varias organizaciones y organismos internacionales como Amnistía Internacional. 
El 21 de enero de 1998, cerca de un centenar de jóvenes Bubis protagonizaron un intento de rebelión popular contra la dictadura de Obiang. El dictador no se contentó con sofocar la rebelión y detener a los autores de la protesta, sino que desencadenó una auténtica orgía de violencia contra la totalidad del pueblo bubi. Más de 800 personas fueron detenidas, torturadas y muchas mutiladas, por tener, o no, alguna relación con los hechos. Bastaba con ser familiar de cualquiera de los supuestos implicados, bastaba con vivir en el mismo pueblo, bastaba con ser bubi. Los discursos del dictador Obiang atizaron el odio étnico contra los bubis y, sintiéndose amparados y estimulados por su jefe, policías y miembros de la seguridad privada del presidente, con su beneplácito, violaron a mujeres y nińas y torturaron hasta la muerte a padres de algunos detenidos.

Yo misma fui detenida, apaleada y torturada por el único y exclusivo motivo de mi relación con Atanasio Bitá.

Sólo las presiones de la comunidad internacional consiguieron detener la caza del bubi desencadenada por Obiang entre enero y agosto de 1998. La persecución contra el pueblo bubi fue denunciada ante los medios de comunicación españoles por varias personalidades del Pais Vasco, como don Juan Ignacio Unda Urzaiz y don Ińaki Anasagasti, a quienes quiero renovar hoy mi agradecimiento personal, el del MAIB y el del pueblo bubi.

La represión de Obiang sobre la población bubi se desencadenó con el pretexto de encontrar e identificar a los manifestantes. Muchos se entregaron voluntariamente, sin que ello disminuyera un ápice la barbarie sobre el pueblo bubi. Basándose en el testimonio bajo tortura de los detenidos, junto con amenazas y chantajes a sus familiares, la dictadura inventó una larga serie de acusaciones infundadas y procedió, en mayo de 1998, a una farsa de juicio, sin garantía alguna, en el que mi marido fue condenado a muerte en rebeldía. Varios miembros del Comité de Coordinación del MAIB, entre los que se encontraba mi marido, optaron por salir del país para continuar la lucha desde el exterior. El 13 de julio de 1998 abandonaron Guinea y pidieron asilo político en la vecina República de Camerún.

Cuando conoció su paradero, el régimen de Obiang intentó eliminar a mi marido y a sus compañeros, pero los servicios secretos de Camerún lo descubrieron a tiempo y lo impidieron. Sólo entonces Obiang optó por la vía diplomática y solicitó la extradición de los miembros del Comité de Coordinación del MAIB, que le fue denegada. No obstante, pese a disfrutar en Camerún de una protección 
policial para evitar que los sicarios de Obiang les asesinaran, la cercanía de fronteras llevó a Bitá y a sus compañeros a pedir y obtener asilo político en la República de Benin, donde yo fui autorizada a reunirme con mi marido.

El inicial período de tranquilidad en Benin se interrumpió cuando supimos que miembros de la seguridad del régimen de Malabo habían secuestrado en Cotonou a un opositor fang. Decidimos entonces trasladarnos a Costa de Márfil, donde disponíamos de buenas relaciones personales con la cúpula del Partido Marfileńo de los Trabajadores y con algunos miembros del Gobierno. Como economista experto en cooperativismo, microcréditos y agronomía, mi marido encontró en Costa de Márfil un amplio campo para trabajar en colaboración con varias ONG locales y distintos ayuntamientos de la zona de Adzope.

La inquietud volvió cuando en octubre de 2005, nuestro amigo Ogou Dapéa, Comisario Comandante de Policía y director general de la Seguridad Nacional de Costa de Márfil, informó a mi marido de que poseía indicios fiables de que el régimen de Obiang quería atentar contra él: le mostró un dossier procedente de Guinea Ecuatorial en el que se detallaban todos los movimientos, datos personales y familiares de mi marido y de toda la cúpula del MAIB. A partir de esa fecha, tanto mi marido como sus compañeros, a quienes inmediatamente informó de ese dossier, extremaron sus precauciones, y el temor se instaló de nuevo en nuestras vidas.

El 4 de febrero de 2006, a las 17 horas, entraron en nuestra casa dos individuos que se presentaron como agentes del servicio secreto de Costa de Márfil. Le dijeron a mi marido que estaba acusado de delitos muy graves y que les tenía que acompañar a la comisaría. Mi marido se resistió inicialmente, pero finalmente, tras encerrarse un momento con ellos en el dormitorio e intercambiar unas palabras, mi marido se calzó y les acompañó mientras los presuntos agentes revolvían la casa para acabar llevando su maletín y su ordenador. Yo intenté ir con ellos, pero me conminaron a que no saliera a la calle, me amenazaron y dieron un portazo. Cuando salí a la calle no supe descubrir qué ruta habían tomado. Volví a casa y llamé al ayudante de mi marido, quien enseguida llamó al director de la Seguridad. A continuación fui a la comisaría más cercana, a la gendarmería y la sub-prefectura, donde tuve que concluir que el asunto era más grave de lo que imaginaba. Nadie tenía conocimiento de ninguna orden de detención que pesara contra mi marido. 
Inmediatamente llamé a los miembros directivos del Partido Marfileño de los Trabajadores e informé de lo sucedido, con todo detalle, a nuestro amigo Ogou Dapéa, director de la Seguridad. El me dijo que iba a dar orden de cierre de todas las fronteras, terrestres y marítimas, y que establecería una vigilancia especial sobre el aeropuerto de Abidján.

La noche del 4 de febrero fue una noche angustiosa para mí y para mis hijos. A las 9 de la mañana del día 5, el director de la Seguridad me comunicó por teléfono que todas las fronteras estaban cerradas y que, si mi marido había sido secuestrado, sería imposible sacarle del país. También me anunció que a lo largo de la mañana vendría a verme a casa en Adzopé. Durante esa mañana hablé también con el Sr. Francis Wodié, Presidente del Partido Marfileño de los Trabajadores, y con la ministra Ngnonsoa.

A las 3 de la tarde del día 5 me informaron de que nuestro buen amigo Ogou Dapéa, había muerto calcinado en el interior de su vehículo tras un extraño accidente. A la incertidumbre sobre el paradero de mi marido se añadía ahora la desesperación por la certeza de la muerte de nuestro amigo en circunstancias sospechosas.

En la mañana del día 6 llegó a mi casa una comisión del Partido Marfileño de los Trabajadores, acompañados por el Comisario de Policía de Adzopé, y me comunicaron el hallazgo del cadáver de mi marido. Había sido asesinado el día 4, horas después de haber sido secuestrado. Le enterramos el sábado 18 de febrero.

Se han barajado distintas hipótesis sobre el asesinato de mi marido. Para mí, y para todos los miembros del MAIB, hay numerosos indicios que nos llevan a creer, sin duda alguna, que el responsable de su muerte es Obiang. Así invita a pensarlo el hecho de que la policía camerunesa impidió un intento anterior, así como los informes obtenidos por el Director de Seguridad de Costa de Marfil. Otros ejemplos de cómo actúan en el exterior los sicarios de Obiang son el secuestro de un opositor fang en Benin durante nuestro exilio en ese país, o el secuestro en Nigeria, el 27 de febrero de 1998, de tres estudiantes bubis (Magín Esara, Marcelino Barila y Marcos Binohari) becados en la Universidad de Owere, posteriormente trasladados de forma ilegal a Malabo en una avioneta particular, acompañados por el ministro de Defensa guineano, Melanio Ebendeng, agentes de seguridad del Estado y altas personalidades del país. 
Obiang ha dado pruebas sobradas de que no sabe lo que es la ley ni la justicia; las confunde con la venganza. Por eso estoy convencida de que la condena a muerte en rebeldía de mi marido en el juicio-farsa de Malabo por los sucesos de enero de 1998 no fue otra cosa que una pública declaración de venganza. Obiang atribuyó entonces a mi marido la responsabilidad por la rebelión popular bubi contra su poder tiránico, y juró vengarse. El secuestro y asesinato de mi marido el día 4 de febrero de 2006 ha sido la ejecución de esa venganza del dictador. Mi deseo, y el del MAIB, es que nos ayuden a poner en marcha una investigación judicial sobre esos hechos.

Señores y señoras diputados, solicito su apoyo para:

Primero, que el peso de la justicia caiga sobre los asesinos de mi marido, Laesa Atanasio Bitá Rope.

Segundo, que el Movimiento por la Autodeterminación de la Isla de Bioko (MAIB), del que mi marido fue presidente hasta el día de su asesinato, pueda continuar y fortalecer su lucha por los derechos del pueblo bubi.

Eskerrik asko 


\section{Bibliografía citada}

AMNISTIA INTERNACIONAL. (1999) Varios autores. Guinea Ecuatorial: un pais sometido al terror y al hostigamiento

BALBOA BONEKE, Juan; NGUEMA ESONO, Fermín (1996), La transición de Guinea Ecuatorial: historia de un fracaso, Madrid: Labrys 54 Ediciones.

BEVERLY, John (1987). <<Anatomía del testimonio>>. Revista de Crítica Literaria Latinoamericana, Año 13, No. 25, pp. 7-16

BIRMINGHAM, David (1995). The Decolonization of Africa. Athens, OH: Ohio UP.

DONNELLY, Jack (1989). Universal Human Rights in Theory and Practice. Ithaca: Cornell UP.

Correspondencia electrónica con Franco Lelli en las siguientes fechas: 17, 25 de agosto de 2013, 9, 15, 22, 24 de septiembre y 5 de octubre de 2013, 27 y 28 de Agosto 2015, New York.

DAVIES, Manuel (2011). La última escalada. Barcelona: Ediciones Mey.

DONNELLY, Jack (1989). Universal Human Rights in Theory and Practice. Ithaca: Cornell UO.

Entrevista telefónica con Franco Lelli, 18 Junio 2015, Palermo (Italia).

FEGLEY, Randall (1989). Equatorial Guinea: An African Tragedy.New York: P. Lang.

LAUB, Dori (1995). "Truth and Testimony: The Process and the Struggle": Trauma: Explorations in Memory. Ed. Cathy Caruth. Baltimore: Johns Hopkins University Press, pp.61-75

LELLI, Franco (2005). OKIRI (Domani). Terni: I.P.S.I.A. "S. PERTINI”

KABUNDA BADI, Mbuyi. (2000) Derechos humanos en África. Teorías y prácticas. Bilbao: Universidad de Deusto.

MELVERN, Linda (2006). Conspiracy to Murder: The Rwandan Genocide. Verso Books.

PARLAMENTO VASCO, Diario de Comisión de derechos humanos y solicitudes ciudadanas, 21.02.2007. Pp.1-15. Web

SÁLET TÓMUM, Fameyong (2011). Guinea Ecuatorial. La solución ("federal"). Justicia, federalismo, libertad. Barcelona: edición del autor.

SMITH, Neil (2008). Uneven Development. Nature, Capital and the Production of Space. Athens, Georgia: The University of Georgia Press. 


\title{
Sitografía
}

\author{
http://www.asodegue.org/ \\ http://www.asodeguesegundaetapa.org/ \\ http://www.state.gov/j/tip/rls/tiprpt/2012/ \\ http://corporate.exxonmobil.com/en/company/worldwideoperations/locations/equatorial-guinea. \\ http://www.wooddatabase.com/lumberidentification/hardwoods/iroko/ \\ http://www.parlamento.euskadi.net/pdfdocs/publi/3/07/09/20030411.pdf \\ http://www.britannica.com/topic/Elf-Aquitaine \\ https://freedomhouse.org/ \\ http://es.rsf.org/ \\ https://www.hrw.org/ \\ https://www.amnesty.org/en/
}

